\title{
Antiplatelet Therapy in Hemodialysis Patients Undergoing Percutaneous Coronary Interventions
}

\author{
Francesco Summaria ${ }^{1, *}$; Maria B. Giannico ${ }^{1}$; Giovanni P. Talarico ${ }^{1}$; Roberto Patrizi $^{1}$ \\ ${ }^{1}$ Department of Cardiology-Policlinico Casilino, Catheter Laboratory, Rome, Italy \\ *Corresponding author: Francesco Summaria, Department of Cardiology-Policlinico Casilino, Catheter Laboratory, Rome, Italy. Tel:+39-0623188448, E-mail: f.summaria@gmail.com
}

Received: February 21, 2015; Accepted: March 17, 2015

\begin{abstract}
Context: Coronary artery disease is highly prevalent among patients with end stage renal disease/hemodialysis (ESRD/HD) and coronary percutaneous interventions (PCI) has been increased by nearly 50\% over the past decade. After PCI with stent placement, guidelines recommend dual antiplatelet therapy (DAPT), but no specifically tailored pharmacotherapy approach is outlined for this frail population, mostly excluded from large randomized clinical trials (RCTs).

Evidence Acquisition: We reviewed current evidences on the use of antiplatelet therapy in patients with ESRD/HD undergoing PCI, focusing on the efficacy and safety of specific agents and their indications for detailed clinical settings.

Results: Clinical setting in HD patients is the principal determinant of the type, onset, combination and duration of the DAPT. However, irrespective clinical setting, in addition to aspirin, clopidogrel is currently the most used antiplatelet agent even if no information derived from RCTs are available in ESRD. Due to the large experience acquired in routine clinical practice, the awareness of safety is higher for clopidogrel than newer antiplatelet agents. Because of lack of data, the use of prasugrel and ticagrelor is actually not recommended. However, in case of high ischemic and acceptable bleeding risk, they may be selectively used in ESRD/HD.

Conclusions: This investigation might contribute to delineate the best treatment options for this high risk population.
\end{abstract}

Keywords: Percutaneous Coronary Interventions; Antiplatelet Therapy; Hemodialysis Patients; Clopidogrel; Prasugrel; Ticagrelor; Drug Eluting Stent

\section{Context}

Due to the pandemic of diabetes (1), increasing rates of hypertension and ageing population $(2,3)$, the incidence and prevalence of end-stage renal disease (ESRD) is rising worldwide $(2,4)$. In this high-risk population, cardiovascular disease is the leading cause of death and morbidity. Coronary artery disease (CAD) is highly prevalent in patients with ESRD and myocardial revascularisation has become an attractive therapeutic option. Compared to percutaneous intervention (PCI), coronary artery bypass grafting (CABG) is associated with higher early and 30 day mortality in ESRD (5). Furthermore, despite increased risks of stent thrombosis and bleedings, coronary stenting in patients on dialysis has been increased by nearly $50 \%$ over the past decade. The dual antiplatelet treatment (DAPT) is the cornerstone treatment after stent implantation, hence the large use of PCI, especially in acute clinical setting, raises the unmet need to optimize this therapy in hemodialysis (HD) patients undergoing PCI.

Since randomized controlled trials (RCTs) are lacking, the current guidelines on percutaneous coronary revascularization are inadequate to provide a specifically tailored therapeutic approach for HD patients. Although many differences have been found principally related to comorbidities and bleedings, the recommendations for general population have been adapted to ESRD setting. A previous study reported a lower probability of bleeding in HD patients with an optimized treatment of anemia (6) supporting an improved safety when antiplatelet therapy is a part of a global therapeutic strategy.

ESRD affects platelet function and coagulation cascade resulting in hemorrhagic tendencies and pro-thrombotic state (7). An abnormal platelet function seems to play a pivotal role in bleeding complications, principally related to defective subendothelial adhesion mediated either by impaired expression of membrane glycoprotein receptor or intrinsic defects of synthesis, storage and release of platelets mediators.

Moreover, uremic platelets show enhanced procoagulant activity (increased thrombin generation, higher concentrations of von Willebrand factor) (8-11) and plateletderived microparticles (12). These microparticles exert a procoagulant activity by overexpressed membrane receptors for factor Va contributing to acceleration of thrombin generation. By note, increased levels of fibrinogen, D-dimer and prothrombin fragments (13-15), as well as reduced, anticoagulant activity of protein $\mathrm{C}$, protein $S$, antithrombin III, plasminogen and tissue type plasminogen activator are frequently found in HD patients

Copyright ( ) 2015, Nephrology and Urology Research Center. This is an open-access article distributed under the terms of the Creative Commons Attribution-NonCommercial 4.0 International License (http://creativecommons.org/licenses/by-nc/4.0/) which permits copy and redistribute the material just in noncommercial usages, provided the original work is properly cited. 
contributing to hypercoagulable state (15). HD patients have an increased risk of site and non-site of access related bleeding complications. Considering the impact of bleeding on adverse outcome after PCI (16-19), the safety/ efficacy balance of antiplatelet therapy in HD patients represents a crucial issue, affecting poor prognosis and contributing to explain underutilization of antithrombotic medications.

\section{Evidence Acquisition}

The scope of this review was to provide an overview of the current evidence on the use of antiplatelets agents actually available, its current and potential use and reviewing the safety and efficacy data in HD patients undergoing PCI.

Considering current guidelines on myocardial revascularization of the European Society of Cardiology (ESC) and of the European association for cardio-thoracic surgery (EACTS) (20), American heart association/american college of cardiology (AHA/ACC) Guidelines for the management of patients with non-ST-elevation acute coronary syndromes (21), a systematic search was performed on MEDLINE, EMBASE and the cochrane central register of controlled trials. Randomized controlled trials (when available), observational studies, together with case series, systematic reviews and expert opinion, comparing different treatment strategies and risk of bleeding were collected, analyzed and discussed.

\section{Results}

Observational studies suggest that patients with chronic kidney disease (CKD) and multivessel disease undergoing revascularization have better short- and long-term survival than those receiving medical therapy alone (22$24)$, especially during acute coronary syndromes (ACS). However, HD patients, having an increased risk of periprocedural ischemic and bleeding complications are frequently excluded from most RCTs on revascularization; hence current treatment strategies are based on retrospective analyses of RCTs and data from registries.

The results from the US renal data system (21981 patients) suggest that CABG should be preferred over PCI in ESRD only for multivessel coronary disease and in appropriately selected non ACS patients (25). The ESC guidelines on myocardial revascularization for ESRD indicated that selection of the most appropriate revascularization strategy must account for the general condition and life expectancy, the least invasive approach being more appropriate in the most fragile and compromised patients, suggesting PCI as a more suitable coronary revascularization strategy.

When PCI is indicated, newer generation drug eluting stent (DES) (class I level of evidence B) (20) should be preferred over bare metal stent (BMS), because of its lower risk of restenosis and improved safety concerns (stent thrombosis) compared to the first generation DES and BMS $(26,27)$.

\subsection{Aspirin}

Although Aspirin in primary prevention by inhibiting the synthesis of renal prostaglandins, over the time, can worsen renal function unbalancing the safety/efficacy profile, in patients with CAD, low dose aspirin is still largely used even despite severe renal impairment.

During ASA therapy, a linear correlation between higher dose and bleeding risk (principally gastrointestinal) has been found. Gastrointestinal bleeding is the third most common ICU admission diagnosis for HD patients ranged from $12 \%$ to $20 \%$ in different reports (28). Hence, a daily long-life maintenance dose from 75 to $100 \mathrm{mg} /$ day seems to be a safe option.

\subsection{Clopidogrel}

Clopidogrel, a second generation oral thienopyridine, is a prodrug converted into active metabolites through a two-step reaction involving cytochrome P450 enzymes, leading to an irreversible blockade of the P2Y12 receptor. Compared with prasugrel and ticagrelor, this conversion results in a lower onset of action and a larger variability in bioavailability. In the CURE study, adding clopidogrel to standard treatment reduced the absolute and relative primary ischemic endpoint only in the middle and upper tertiles of renal function, without any significant improvement in outcome in lower tertile (eGFR, < $64 \mathrm{~mL}$ / min) increasing minor and moderately major and lifethreatening bleeding (29).

\subsection{Prasugrel}

Prasugrel is a third generation oral thienopyridine, which is a specific, irreversible antagonist of the platelet adenosine 5'-diphosphate P2Y12 receptor. Prasugrel has more potent antiplatelet activity, faster onset of action and less interpatient variability compared with clopidogrel. These pharmacodynamic properties in TRITON-TIMI 38 study led prasugrel to be more effective than clopidogrel in preventing ischemic events in patients with ACS undergoing PCI. Although in ESRD, exposure to the active metabolite of prasugrel is lower than healthy control, this does not affect platelet aggregation (30). Hence, during prasugrel therapy, a dose adjustment based on renal function is not recommended, but the drug label reminded the limited experience in stage $5 \mathrm{CKD}$, as in TRITON-TIMI 38 study a post-hoc subgroup analysis could be performed only for patients until stage 3 to 4 CKD (1490 patients).

\subsection{Ticagrelor}

Ticagrelor is a cyclopentyltriazolopyrimidine, with a plasma half-life of approximately 6 - 12 hours and unlike clopidogrel and prasugrel, requires a dual daily administration and binding reversibly to the P2Y12 receptor. Ticagrelor is metabolized minimally from the kidneys.

Its effectiveness in ACS was tested in the PLATO trial, 
in which CKD subgroup well represented consisting in nearly $21 \%$ of the overall study population.

In 3237 patients with stages 3 to $4 \mathrm{CKD}$, ticagrelor was associated with a higher absolute $(4.7 \%$ vs $1.0 \%$ ) and relative (23\% vs $10 \%)$ reduction of primary ischemic end point than clopidogrel.

Similarly to the overall PLATO population, patients with CKD had $4 \%$ absolute risk reduction in all-cause mortality (31) without any significant increase in bleedings (i.e. major and fatal bleedings, non-coronary bypass related major bleedings). However, if the more contemporary Modification of Diet in Renal Disease formula is used instead of the Cockcroft-Gault equation, as recommended by The National Kidney Foundation, the primary end point and mortality became statistically significant limiting the superiority of ticagrelor over clopidogrel only in stages 3 to 4 CKD (32). This favorable effect probably related to a pleiotropic non-antiplatelet related action (increased circulating levels of adenosine) needs to be definitively confirmed.

Similarly to clopidogrel and prasugrel, ticagrelor requires no dose adjustment based on renal function, but its use in patients with ESRD is not recommended because of lack of data in this specific subpopulation.

\subsection{Pre-Treatment With P2Y12 Inhibitors}

\subsubsection{Clopidogrel}

The rationale of pre-treatment with P2Y12 inhibitors is based on the observation that periprocedural ischemic complications are related to the degree of intraprocedural platelet inhibition, following the results of old clopidogrel studies. In these trials, the delay between clopidogrel $300 \mathrm{mg}$ loading dose and PCI was adequate to ensure circulating effective levels of active metabolites. Recent meta-analysis evaluating the clopidogrel pre-treatment, showed a benefit related to the severity of clinical presentation; no improvement in ischemic outcomes with more bleedings in PCI for stable angina (SA), but a significant reduction in cardiovascular events (driven mainly by myocardial infarction) without significant excess in major bleedings in ACS (33).

\subsubsection{Prasugrel and Ticagrelor}

In the ACCOAST study, a pretreatment strategy with prasugrel in NSTE-ACS failed to reduce the primary endpoint (a composite of cardiovascular death, myocardial infarction, stroke, urgent revascularization and bail-out GPIIb/IIIa inhibitor use) and was stopped prematurely for major bleedings concerns (34). A similar result was also obtained in stable clinical setting of the ARMYDA-5 study, in which a pretreatment with prasugrel versus $600 \mathrm{mg}$ clopidogrel loading dose failed to reduce ischemic events with an excess risk of bleeding.

The recently published ATLANTIC study mentioned that prehospital administration of ticagrelor did not improve pre- primary PCI coronary reperfusion, but is safe (similar rates of major bleeding) with a significant reduction in stent thrombosis. Moreover, the study population, differently from HD patients, had a lower ischemic risk and TRA approach (contraindicated in HD patients) had been largely used (35).

Considering all the above results, as the absence of data for HD patients and the higher basal risk of bleeding:

A. Pretreatment with prasugrel is contraindicated either in SA or NSTEMI.

B. Clopidogrel pretreatment with $300 \mathrm{mg}$ loading dose of at least 6 hours before PCI is recommended in a stable setting.

C. Clopidogrel $600 \mathrm{mg}$ loading dose should be used only in NSTEMI undergoing early invasive strategy with PCI (delay time $<3$ hour) and in STEMI undergoing primary PCI.

D. Ticagrelor pretreatment in primary PCI is not contraindicated, but not recommended considering scarce specific data for HD patients.

\subsection{Clinical Settings}

The clinical setting is the principal determinant of the type, onset, combination and duration of the antithrombotic therapy (Table 1).

\subsubsection{Stable Coronary Artery Disease}

As bleeding hazards might be increased, antiplatelet agents in HD patients should be cautiously used in a stable setting with low annual risks of cardiovascular events and medically-alone managed conservative strategy. Nevertheless, when an ischemia driven coronary intervention is performed, a DAPT is strongly recommended to avoid stent thrombosis and adverse coronary events.

Table 1. Evidence, Duration and Type of Antiplatelet Related to Clinical Setting

\begin{tabular}{lccccc}
\hline Clinical Setting & ASA & Clopidogrel & Prasugrel & Ticagrelor & DAPT duration \\
\hline Stable Angina & yes & yes & no & no & $\begin{array}{c}\text { 1 month for (BMS) 6 months (newer DES) } \\
12 \text { months (first generation DES) }\end{array}$ \\
NSTEMI & yes & $\begin{array}{c}\text { yes (class I level of } \\
\text { evidence B)(21) }\end{array}$ & $\begin{array}{c}\text { only in stented patients if } \\
\text { not contraindicated }\end{array}$ & $\begin{array}{c}\text { yes (class I level of } \\
\text { evidence B) (21) }\end{array}$ & 12 months irrespective type of stent \\
STEMI & yes & $\begin{array}{c}\text { yes (class I level of } \\
\text { evidence C)(20) }\end{array}$ & $\begin{array}{c}\text { yes (class I level of evi- } \\
\text { dence B)(20) }\end{array}$ & $\begin{array}{c}\text { yes (class I level of } \\
\text { evidence B)(20) }\end{array}$ & 12 months irrespective type of stent \\
\hline
\end{tabular}


DAPT includes a 150 - $300 \mathrm{mg}$ oral loading dose of acetylsalicylic acid (ASA) (or 80 - $150 \mathrm{mg}$ i.v.) in patients never treated, followed by 75 - $100 \mathrm{mg}$ daily plus a clopidogrel $300 \mathrm{mg}$ loading dose, if the procedure is performed from 3 to 6 hours after load or $600 \mathrm{mg}$ loading dose, if performed prior to 3 hours after load, followed by $75 \mathrm{mg}$ daily $(36,37)$.

Double clopidogrel maintenance dose has been proposed in high thrombotic risk patients (e.g. diabetes, recurrent myocardial infarction, stent thrombosis, complex lesion, non-responders) (38). In particular, in hemodyalisis patients, no scientific evidences of short or long term ischemic benefit are available for double dose clopidogrel regimen, so that it would not be advisable for its higher bleeding concerns. Despite newer more potent P2Y12-receptor antagonist, in stable non ACS clinical setting, as guidelines reported, only clopidogrel is recommended.

As single antiplatelet therapy, ASA is followed lifelong after the first month (if BMS is used) or after the sixth month (if new generation DES is used) $(38,39)$.

\subsubsection{Acute Coronary Syndromes}

The American national kidney foundation guidelines found that all HD patients with ACS should be managed equally to non-dialysis patients including DAPT and PCI.

In ACS, renal function is significantly correlated with MACE. In particular compared to patients with normal function, HD patients have a 30- and 10-fold higher inhospital mortality during STEMI and NSTEMI, respectively. This worse clinical outcome seems to be related to different mechanisms:

A. more severe coronary involvement (3 vessels or left main disease in about 40\%)

B. higher comorbidities rate

C. underutilization of cardiac medications with possible and/or suspected sub-optimal response

D. disease and/or drug related excess of bleeding

E. high risk of restenosis and stent thrombosis

To balance the efficacy/safety ratio, a systematic approach based on individual integrated ischemic and bleeding risk assessment should be used in all ACS patients undergoing PCI to individualize DAPT and to guide the time of revascularization.

Many risks calculators have been proposed, but at present the more validated and widely used are the GRACE risk score and CRUSADE bleeding risk calculator. Concerning the GRACE, a serum creatinine level $>4 \mathrm{mg} / \mathrm{dL}$ is one of the most powerful parameters related to an in creased risk of in-hospital and 6-month mortality, hence when an ACS occurs, HD patients very often are at high ischemic risk. Similarly for CRUSADE bleeding risk calculator, a creatinine clearance $<15 \mathrm{~mL} / \mathrm{min}$ confers a score of 39 confirming the impact of an impaired renal function on risk of bleeding during ACS.

Indeed transradial access (TRA) by dramatically reduc- ing the rate of vascular bleeding leads to a significant reduction of adverse events and mortality, especially in high-risk subgroups (40). However, HD patients are not elective candidates to TRA because of the risk of radial thrombosis and occlusion. For this reason, the Fistula First Breakthrough Initiative recommends avoiding the use of TRA in patients with HD and advanced CKD, leaving the DAPT a major concern in this combined ischemic + hemorrhagic risk population.

\subsubsection{Non-ST-Segment Elevation Myocardial Infarction}

In HD patients, management of NSTEMI has less consensus than that of STEMI and stable angina. The 2014 ACC/ AHA guidelines on management of NSTEMI report no specific recommendations for antiplatelet use in HD patients. The main reason of this gap must be sought in the wider spectrum of risk along with different timing and type of revascularization.

DAPT includes aspirin with an oral pre-procedural loading dose of 150 - $300 \mathrm{mg}$ (or 80 - $150 \mathrm{mg}$ i.v.), followed by 75 -100 mg P. O. daily and a P2Y12-receptor antagonist.

In particular, guidelines (21) stipulate that Clopidogrel or Ticagrelor (Class I Level of evidence B) is the first treatment choice.

According to the TRITON study design and the results of TRILOGY-ACS and ACCOAST, prasugrel is not recommended for "upfront" therapy in patients with NSTEMI, but only in "stented" patients.

In particular, in the TRITON-TIMI 38 study, prasugrel compared to clopidogrel, resulted in a $19 \%$ reduction of ischemic events in moderate to high risk ACS patients undergoing PCI, started in the catheterization laboratory after diagnostic angiography in thienopyridine-naive patients. However, the greater protective effects toward ischemic events were partially counterbalanced by an increased risk of bleeding and the net clinical benefit (a combined ischemic and TIMI major hemorrhages) remained in favor of prasugrel only in the high ischemic risk CKD subgroup as diabetic patients and stent thrombosis presenting with ACS (41).

In the PLATO, patients with moderate to high-risk NSTEMI undergoing PCI had significantly lower primary endpoint occurrence with ticagrelor than clopidogrel $(11.4 \%$ vs. 13.9\%). The rate of TIMI major non-CABG-related bleeding was higher in ticagrelor group (2.8\%) than clopidogrel group (2.2\%), but TIMI major CABG-related bleeding was less frequent than clopidogrel. There was no difference in the overall rates of fatal hemorrhage $(0.3 \%$ in both groups) despite a higher rate of fatal intracranial hemorrhage in the ticagrelor group ( $0.1 \%$ vs. $0.001 \%$; $\mathrm{P}<0.02$ ).

The CURRENT-OASIS 7 trial tested whether a double dose regimen of clopidogrel (600 mg loading dose followed by $150 \mathrm{mg}$ daily dose for 7 days, then $75 \mathrm{mg}$ daily) was superior to standard dose in ACS patients. Overall, the higher dose regimen conferred similar results than standard dose in major adverse cardiac events at the cost of 
increased TIMI major bleedings and need for blood transfusion, resulting in a wrong way, especially in high risk of bleeding HD patients (42).

\subsubsection{ST-Segment Elevation Myocardial Infarction}

Due to the increased hemorrhagic risk associated with thrombolytic therapy, primary PCI should be considered the preferred reperfusion therapy in HD patients. Patients undergoing primary PCI should receive a combination of DAPT with ASA and a P2Y12 receptor blocker as early as possible.

An oral loading dosage of ASA 150 - 300 mg (or i.v. 80 $150 \mathrm{mg}$ ) followed by 75 - $100 \mathrm{mg}$ P.O. daily should be associated with the preferred P2Y12 inhibitors, prasugrel (60 mg P.O. loading dose, $10 \mathrm{mg}$ maintenance dose) or ticagrelor (180 mg P.O. loading dose, $90 \mathrm{mg}$ maintenance dose b.i.d.) $(43,44)$ because of a more rapid onset of action and greater potency and superiority to clopidogrel in large outcome trials $(45,46)$ (Class I Level of evidence B) Clopidogrel should be used preferably when prasugrel or ticagrelor is either not available or contraindicated (Class I Level of evidence C).

In the pre-specified subgroups of patients with STEMI undergoing PCI in the TRITON-TIMI 38 trial, the benefit of prasugrel was consistent for the primary endpoint (prasugrel $10.0 \%$ vs. clopidogrel 12.4\%, HR 0.79; 95\%, CI 0.65 - 0.97, P = 0.02), without a significant increase in nonCABG-related bleeding risk (2.4\% vs. $2.1 \%$, HR 1.11; 95\%, CI $0.70-1.77, \mathrm{P}=0.65)$. There was a lower risk of stent thrombosis (1.6\% vs. $2.8 \%$, HR 0.58; 95\%, CI $0.36-0.93, \mathrm{P}=0.02$ ), as well as cardiovascular mortality (47) in favor of prasugrel at 30 day and 15 month follow-up (2.4\% vs. 3.4\%, HR 0.74; $95 \%, C I 0.50-1.09, P=0.129)$. In the subset of patients with STEMI randomized in the PLATO trial, the benefit of ticagrelor over clopidogrel for the primary endpoint (9.4\% vs. $10.8 \%$, HR 0.87 ) (48), was consistent with the overall results, without increased bleeding (TIMI non-CABG major bleedings $2.5 \%$ vs. 2.2\%, HR 1.09; 95\% CI $0.80-1.48, \mathrm{P}=0.60$ ), but with a trend towards a lower risk of cardiovascular mortality at one year. In a pooled analysis of 48599 patients, of whom 94\% presented with ACS and $84 \%$ had PCI, prasugrel and ticagrelor associated with a mortality benefit and no significant excess of major bleeding among STEMI patients (49).

In conclusion, Prasugrel is contraindicated in patients with prior stroke or TIA and generally not recommended for patients aged 75 years and older. Despite the fact, if treatment is necessary in the $\geq 75$ years age or low body weight $(<60 \mathrm{~kg})$, after a careful individual risk benefit evaluation, following a loading dose of $60 \mathrm{mg}$, a reduced maintenance dose of $5 \mathrm{mg}$ should be prescribed resulting in greater platelet inhibition than clopidogrel $75 \mathrm{mg} /$ day and similar bleeding rates (50).

Both prasugrel and ticagrelor are contraindicated in patients with prior hemorrhagic stroke or with moderate to severe liver disease.

\subsubsection{Special Considerations}

\subsubsection{Stent Selection and DAPT Compliance}

Taking into account the rates of restenosis and stent thrombosis in HD patients, newer generation DES should be preferred over BMS and first generation DES (Class I Level of evidence B) (20).

Among DES, despite no differences found between paclitaxel and limus eluting stent in MACE and target lesion revascularization $(51,52)$, the newer everolimus and zotarolimus eluting stent should be preferred for the lower rates of stent thrombosis and given the possibility of discontinuing, if necessary, DAPT prior to 12 month (53, 54). Table 2 summarizes device characteristics, indication and potential use of currently available stents in HD patients (55).

\begin{tabular}{|c|c|c|c|c|c|c|}
\hline Type of Stent & Restenosis & $\begin{array}{c}\text { Stent } \\
\text { Thrombosis }\end{array}$ & $\begin{array}{c}\text { Studies } \\
\text { in HD }\end{array}$ & $\begin{array}{c}\text { Stent-Related DAPT } \\
\text { Duration }\end{array}$ & $\begin{array}{c}\text { Potential Indication in } \\
\text { HD pts }\end{array}$ & $\begin{array}{c}\text { Guidelines } \\
\text { Recommendations }\end{array}$ \\
\hline BMS & high & low & yes & 1 month & $\begin{array}{l}\text { limited due to high rate of } \\
\text { restenosis }\end{array}$ & not preferred \\
\hline $\begin{array}{l}\text { First } \\
\text { generation DES }\end{array}$ & low & high & yes & 12 month & yes & $\begin{array}{l}\text { considered but not } \\
\text { recommended }\end{array}$ \\
\hline $\begin{array}{l}\text { Newer } \\
\text { generation DES }\end{array}$ & very low & $\begin{array}{l}\text { very low (lower } \\
\text { than BMS) }\end{array}$ & yes & $\begin{array}{l}1 \text { month (zotarolimus } \\
\text { eluting stent) }(55) 3 \text { month } \\
\text { (everolimus eluting stent, CE } \\
\text { mark) } 6 \text { month Overall }(20)\end{array}$ & Yes preferred & $\begin{array}{l}\text { class I level of } \\
\text { evidence B (c) }\end{array}$ \\
\hline DCS & low & low & none & $\begin{array}{c}\text { Virtually } 1 \text { month if } \\
\text { confirmed (leaders free } \\
\text { trial) }(56)\end{array}$ & $\begin{array}{l}\text { yes considering the } \\
\text { possible shortening of } \\
\text { DAPT }\end{array}$ & not evaluated \\
\hline BVS & low & & none & 12 month & $\begin{array}{l}\text { limited for high calcified } \\
\text { coronary lesions }\end{array}$ & not evaluated \\
\hline
\end{tabular}

\footnotetext{
a Abbreviations: BMS: Bare metal stent, BVS: Bioresorbable vascular scaffold, DCS: Drug coated stent DES: Drug eluting stent.
} 
There is a significant gap in the literature concerning the outcomes related to DAPT duration. Most HD patients, prematurely discontinue thienopyridine prior to one year after PCI, data collected from the US Renal Data System showed that at 3 month, $82 \%$ of patients who received a DES were still on thienopyridine; the proportion decreased to $40 \%$ at 12 -month, while in patients who received a BMS, these rates were lower (70\% and $26 \%$ at 3 and 12 month). However, in DES patients, there was evidence of higher risk of death or MI associated with thienopyridine discontinuation, in BMS patients no increase in ischemic events was recorded, but possibly lower risk of major bleeding with drug discontinuation. Interestingly in this registry, the rate of myocardial infarction, death and repeated revascularization were 6 to 10 fold higher than the general population suggesting that the worse outcome of patients on dialysis is a possible indication to extend the DAPT over 12 month (56). However, these results are not able to provide a definitive indication, further studies are needed in this field.

\subsubsection{Antiplatelet Tests Assessment}

Patients with ESRD exhibit high residual platelet reactivity on treatment with clopidogrel regardless of diabetes (57). Hyporesponsiveness to thienopyridines in CKD is associated with increased risk of stent thrombosis and adverse events, including mortality $(58,59)$. Despite the fact, guidelines confirm no evidence for routine platelets assessment and phenotype testing; in HD patients undergoing PCI platelet function testing has been suggested (58), especially among those who experience thrombotic events despite DAPT. Three small studies (60-62) with very short follow-up tested and confirmed a more intense antiplatelet effect with prasugrel or ticagrelor compared to high dose clopidogrel in HD patients. However, different considerations should be made about these studies:

A. In the prasugrel study (21 patients), no bleeding events at 30 days were recorded, but concomitant use of ASA was only in the half of the patients. Patients with previous stroke, ACS, severe bleedings, chronic oral anticoagulant, PCI and CABG were excluded, 19\% remained hyporesponsive even on prasugrel.

B. The two ticagrelor studies (respectively 20 patients and 25 patients) $(60,61)$ were performed principally in a stable setting, $13 \%$ of patients excluded for low compliance, $20 \%$ had dyspnea and/or bleeding.

\section{Conclusions}

Cardiovascular events are responsible for $44 \%$ of death in HD patients (63). However, in the last decade, there has been a gradual decline in mortality principally due to 30 day reduced mortality for STEMI. This reduction must be related to either large use of antiplatelet agents and statin (64) or increased use of coronary revascularization. While overall use of coronary revascularization has changed little over the past ten years, preliminary data indicate an increased use of early PCI in STEMI. Despite its large use, no informations derived from RCTs are available for clopidogrel in patients with severe renal dysfunction. However, the awareness of safety is higher for clopidogrel than prasugrel or ticagrelor, mostly due to the large experience occurred in routine clinical practice (62) (Table 3).

Considering the evidence provided, it is premature to suggest substantial changes in current clinical practice. Despite previously discussed limitations, Clopidogrel maintains a central role in patients undergoing PCI. The use of point-of-care assays could be useful to overcome the commonly hyporesponsiveness to clopidogrel widening the use of prasugrel and ticagrelor.

Summarizing the recommendations for clinical practice (Table 4) is as follows;

A. Aspirin should be administered at low dose regimens (<100 mg) long-life.

B. Clopidogrel remains the only choice in case of PCI in a stable clinical setting and despite clinical setting, in patients requiring P2Y12-inhibiting therapy with a basal high risk of bleeding (included patients taking oral anticoagulant therapy).

C. Even if not recommended, Prasugrel should be considered only in patients with ACS undergoing PCI with an individual ischemic risk and/or thrombotic burden higher than bleeding risk (i.e. diabetic, STEMI, stent thrombosis in clopidogrel treated). It should be used with caution in patients with low weight and the elderly ( $>75$ years) possibly at $5 \mathrm{mg}$ reduced dose. It is contraindicated in patients with a prior transient ischemic attack/stroke or previous intracranial hemorrhage.

D. Although ticagrelor can be used across the spectrum of ACS until stage 4 CKD patients, its use should be carefully considered in patients with poor compliance given its twice-daily administration.

E. Ticagrelor is contraindicated in patients with prior hemorrhagic stroke and severe hepatic impairment and cautiously used in patients treated with potent inhibitors or inducers of CYP3A due to potential drug interactions.

Table 3. Evidence Comparison Between Different Antiplatelet

\begin{tabular}{|c|c|c|c|c|}
\hline \multirow{3}{*}{ Antiplatelet } & \multicolumn{4}{|c|}{ Evidence in Hemodialysis } \\
\hline & \multicolumn{2}{|c|}{ Acute Coronary Syndromes } & \multicolumn{2}{|c|}{ Stable Angina } \\
\hline & RCT's & registries & RCT's & Registries \\
\hline Clopidogrel & none & US renal data system (56) & none & US renal data system (56) \\
\hline Prasugrel & none & US renal data system (59 pts) (56) & 21 pts (60) & $12+16$ pts $(30)$ \\
\hline Ticagrelor & none & none & 20 pts (61) 25 pts (62) & none \\
\hline
\end{tabular}




\begin{tabular}{|c|c|c|}
\hline Antiplatelet & Pro & Cons \\
\hline \multicolumn{3}{|l|}{ Clopidogrel } \\
\hline & awareness of safety & prodrug \\
\hline & large registries data & lower onset of action \\
\hline & less bleedings & larger variability in bioavailability \\
\hline & & no RCT's confirmed efficacy \\
\hline \multicolumn{3}{|l|}{ Prasugrel } \\
\hline & high effectiveness in ACS STEMI subgroup & potentially harmful in prior TIA/Stroke \\
\hline & high effectiveness in stent thrombosis & suspected platelet hyporesponsiveness in HD \\
\hline & & limited clinical experience in HD \\
\hline \multicolumn{3}{|l|}{ Ticagrelor } \\
\hline & efficacy in broad spectrum of ACS & more hemorrhagic stroke \\
\hline & less CABG-related bleeding & harmful in severe hepatic impairment \\
\hline & less increase of fatal bleedings, and & twice daily administration \\
\hline & non-CABG related bleedings in CKD & limited clinical experience in HD \\
\hline
\end{tabular}

In conclusion, current guidelines are not HD centered then the primary goal to improve the quality of care preserving patient's health and safety is not simple to accomplish in clinical practice and should be guaranteed with a personalized medicine approach.

\section{Authors' Contributions}

Study concept and design: Francesco Summaria. Acquisition of data: Francesco Summaria and Maria B. Giannico. Analysis and interpretation of data: Francesco Summaria, Maria B. Giannico, Giovanni P. Talarico and Roberto Patrizi. Drafting of the manuscript: Francesco Summaria and Maria B. Giannico. Critical revision of the manuscript for important intellectual content: Francesco Summaria, Maria B. Giannico, Giovanni P. Talarico and Roberto Patrizi.

\section{References}

1. Haroun MK, Jaar BG, Hoffman SC, Comstock GW, Klag MJ, Coresh J. Risk factors for chronic kidney disease: a prospective study of 23,534 men and women in Washington County, Maryland. J Am Soc Nephrol. 2003;14(11):2934-41.

2. Islam TM, Fox CS, Mann D, Muntner P. Age-related associations of hypertension and diabetes mellitus with chronic kidney disease. BMC Nephrol. 2009;10:17.

3. Coresh J, Selvin E, Stevens LA, Manzi J, Kusek JW, Eggers P, et al Prevalence of chronic kidney disease in the United States. JAMA. 2007;298(17):2038-47.

4. Ritz E, Bakris G. World Kidney Day: hypertension and chronic kidney disease. Lancet. 2009;373(9670):1157-8.

5. Darlington A, Ferreiro JL, Ueno M, Suzuki Y, Desai B, Capranzano P, et al. Haemostatic profiles assessed by thromboelastography in patients with end-stage renal disease. Thromb Haemost. 2011;106(1):67-74.

6. Sanchez Perales MC, Vazquez E, Garcia Cortes MJ, Borrego FJ, Borrego J, Perez del Barrio P, et al. [Platelet antiaggregation and hemorrhagic risk in hemodialysis]. Nefrologia. 2002;22(5):456-62.

7. Di Minno G, Cerbone A, Usberti M, Cianciaruso B, Cortese A Farace MJ, et al. Platelet dysfunction in uremia. II. Correction by arachidonic acid of the impaired exposure of fibrinogen re- ceptors by adenosine diphosphate or collagen. J Lab Clin Med. 1986;108(3):246-52.

8. Moal V. Impaired expression of glycoproteins on resting and stimulated platelets in uraemic patients. Nephrol Dial Transpl. 2003;18(9):1834-41.

9. Kaw D, Malhotra D. Platelet dysfunction and end-stage renal disease. Semin Dial.2006;19(4):317-22.

10. Bonomini M, Dottori S, Amoroso L, Arduini A, Sirolli V. Increased platelet phosphatidylserine exposure and caspase activation in chronic uremia. J Thromb Haemost. 2004;2(8):1275-81.

11. Ando M, Iwata A, Ozeki Y, Tsuchiya K, Akiba T, Nihei H. Circulating platelet-derived microparticles with procoagulant activity may be a potential cause of thrombosis in uremic patients. Kidney Int. 2002;62(5):1757-63.

12. Irish A. Cardiovascular disease, fibrinogen and the acute phase response Associations with lipids and blood pressure in patients with chronic renal disease. Atherosclerosis. 1998;137(1):133-9.

13. Mercier E, Branger B, Vecina F, Al-Sabadani B, Berlan J, Dauzat M, et al. Tissue factor coagulation pathway and blood cells activation state in renal insufficiency. Hematol J. 2001;2(1):18-25.

14. Catena C, Zingaro L, Casaccio D, Sechi LA. Abnormalities of coagulation in hypertensive patients with reduced creatinine clearance. Am J Med. 2000;109(7):556-61.

15. Vaziri ND, Shah GM, Winer RL, Gonzales E, Patel B, Alikhani S, et al. Coagulation cascade, fibrinolytic system, antithrombin III, protein $C$ and protein $S$ in patients maintained on continuous ambulatory peritoneal dialysis. Thrombosis Res.1989;53(2):173-80.

16. Rao SV, O'Grady K, Pieper KS, Granger CB, Newby LK, Van de Werf $\mathrm{F}$, et al. Impact of bleeding severity on clinical outcomes among patients with acute coronary syndromes. Am J Cardiol. 2005;96(9):1200-6

17. Eikelboom JW, Mehta SR, Anand SS, Xie C, Fox KA, Yusuf S. Adverse impact of bleeding on prognosis in patients with acute coronary syndromes. Circulation. 2006;114(8):774-82.

18. Ndrepepa G, Berger PB, Mehilli J, Seyfarth M, Neumann FJ, Schomig A, et al. Periprocedural bleeding and 1-year outcome after percutaneous coronary interventions: appropriateness of including bleeding as a component of a quadruple end point. J Am Coll Cardiol. 2008;51(7):690-7.

19. Mehran R, Pocock SJ, Stone GW, Clayton TC, Dangas GD, Feit F, et al. Associations of major bleeding and myocardial infarction with the incidence and timing of mortality in patients presenting with non-ST-elevation acute coronary syndromes: a risk model from the ACUITY trial. Eur Heart J. 2009;30(12):1457-66.

20. Authors/Task Force M, Windecker S, Kolh P, Alfonso F, Collet JP, Cremer J, et al. 2014 ESC/EACTS Guidelines on myocardial revas- 
cularization: The Task Force on Myocardial Revascularization of the European Society of Cardiology (ESC) and the European Association for Cardio-Thoracic Surgery (EACTS)Developed with the special contribution of the European Association of Percutaneous Cardiovascular Interventions (EAPCI). Eur Heart J. 2014;35(37):2541-619.

21. Amsterdam EA, Wenger NK, Brindis RG, Casey DJ, Ganiats TG, Holmes DJ, et al. 2014 AHA/ACC guideline for the management of patients with non-ST-elevation acute coronary syndromes: executive summary: a report of the American College of Cardiology American Heart Association Task Force on Practice Guidelines. Circulation. 2014;130(25):2354-94.

22. Chertow GM, Normand SL, McNeil BJ. "Renalism": inappropriately low rates of coronary angiography in elderly individuals with renal insufficiency. JAm Soc Nephrol. 2004;15(9):2462-8.

23. Hemmelgarn BR, Southern D, Culleton BF, Mitchell LB, Knudtson ML, Ghali WA, et al. Survival after coronary revascularization among patients with kidney disease. Circulation. 2004;110(14):1890-5.

24. Reddan DN, Szczech LA, Tuttle RH, Shaw LK, Jones RH, Schwab SI, et al. Chronic kidney disease, mortality, and treatment strategies among patients with clinically significant coronary artery disease. JAm Soc Nephrol. 2003;14(9):2373-80.

25. Chang TI, Shilane D, Kazi DS, Montez-Rath ME, Hlatky MA, Winkelmayer WC. Multivessel coronary artery bypass grafting versus percutaneous coronary intervention in ESRD. J Am Soc Nephrol. 2012;23(12):2042-9.

26. Tsai TT, Messenger JC, Brennan JM, Patel UD, Dai D, Piana RN, et al. Safety and efficacy of drug-eluting stents in older patients with chronic kidney disease: a report from the linked CathPCI Registry-CMS claims database. J Am Coll Cardiol. 2011;58(18):1859-69.

27. Shenoy C, Boura J, Orshaw P, Harjai KJ. Drug-eluting stents in patients with chronic kidney disease: a prospective registry study. PLoS One. 2010;5(11):e15070.

28. Arulkumaran N, Annear NM, Singer M. Patients with end-stage renal disease admitted to the intensive care unit: systematic review. BrJ Anaesth. 2013;110(1):13-20.

29. Keltai M, Tonelli M, Mann JF, Sitkei E, Lewis BS, Hawken S, et al Renal function and outcomes in acute coronary syndrome: impact of clopidogrel. Eur J Cardiovasc Prev Rehabil. 2007;14(2):312-8.

30. Small DS, Wrishko RE, Ernest Ii CS, Ni L, Winters KJ, Farid NA, et al. Prasugrel pharmacokinetics and pharmacodynamics in subjects with moderate renal impairment and end-stage renal disease. $J$ Clin Pharm Ther. 2009;34(5):585-94.

31. James S, Budaj A, Aylward P, Buck KK, Cannon CP, Cornel JH, et al. Ticagrelor versus clopidogrel in acute coronary syndromes in relation to renal function: results from the Platelet Inhibition and Patient Outcomes (PLATO) trial. Circulation. 2010;122(11):1056-67.

32. Capodanno D, Angiolillo DJ. Antithrombotic therapy in patients with chronic kidney disease. Circulation. 2012;125(21):2649-61.

33. Bellemain-Appaix A, O'Connor SA, Silvain J, Cucherat M, Beygui F, Barthelemy O, et al. Association of clopidogrel pretreatment with mortality, cardiovascular events, and major bleeding among patients undergoing percutaneous coronary intervention: a systematic review and meta-analysis. JAMA. 2012;308(23):2507-16.

34. Montalescot G, Bolognese L, Dudek D, Goldstein P, Hamm $\mathrm{C}$, Tanguay JF, et al. Pretreatment with prasugrel in non-STsegment elevation acute coronary syndromes. $N$ Engl $J$ Med. 2013;369(11):999-1010.

35. Montalescot G, van 't Hof AW, Lapostolle F, Silvain J, Lassen JF, Bolognese L, et al. Prehospital ticagrelor in ST-segment elevation myocardial infarction. NEngl J Med. 2014;371(11):1016-27.

36. Silber S, Albertsson P, Aviles FF, Camici PG, Colombo A, Hamm C et al. Guidelines for percutaneous coronary interventions. The Task Force for Percutaneous Coronary Interventions of the European Society of Cardiology. Eur Heart J. 2005;26(8):804-47.

37. Patrono C, Garcia Rodriguez LA, Landolfi R, Baigent C. Low-dose aspirin for the prevention of atherothrombosis. $N$ Engl J Med. 2005;353(22):2373-83.

38. Patrono C, Andreotti F, Arnesen H, Badimon L, Baigent C, Collet JP, et al. Antiplatelet agents for the treatment and prevention of atherothrombosis. Eur Heart J. 2011;32(23):2922-32.
39. Collaboration AT. Collaborative meta-analysis of randomised trials of antiplatelet therapy for prevention of death, myocardial infarction, and stroke in high risk patients. BMJ. 2002;324(7329):7186.

40. Summaria F, Romagnoli E, De Luca L, Mustilli M, Pagnanelli A Feasibility and safety of transradial approach and bivalirudin treatment in elderly patients undergoing early invasive strategy for ACS: 'The OLDER Research Project' preliminary study. JCardiovasc Med (Hagerstown). 2012;13(5):351-2.

41. Wiviott SD, Braunwald E, Angiolillo DJ, Meisel S, Dalby AJ, Verheugt FW, et al. Greater clinical benefit of more intensive oral antiplatelet therapy with prasugrel in patients with diabetes mellitus in the trial to assess improvement in therapeutic outcomes by optimizing platelet inhibition with prasugrel-Thrombolysis in Myocardial Infarction 38. Circulation. 2008;118(16):1626-36.

42. Current-Oasis Investigators, Mehta SR, Bassand JP, Chrolavicius S, Diaz R, Eikelboom JW, et al. Dose comparisons of clopidogrel and aspirin in acute coronary syndromes. $N$ Engl J Med. 2010;363(10):930-42.

43. Wallentin L, Becker RC, Budaj A, Cannon CP, Emanuelsson H, Held $\mathrm{C}$, et al. Ticagrelor versus clopidogrel in patients with acute coronary syndromes. N Engl J Med. 2009;361(11):1045-57.

44. Wiviott SD, Braunwald E, McCabe CH, Montalescot G, Ruzyllo W, Gottlieb S, et al. Prasugrel versus clopidogrel in patients with acute coronary syndromes. N Engl J Med. 2007;357(20):2001-15.

45. Long-term results of prospective randomised study of coronary artery bypass surgery in stable angina pectoris. European Coronary Surgery Study Group. Lancet. 1982;2(8309):1173-80.

46. Eleven-year survival in the Veterans Administration randomized trial of coronary bypass surgery for stable angina. The Veterans Administration Coronary Artery Bypass Surgery Cooperative Study Group. N Engl J Med. 1984;311(21):1333-9.

47. Montalescot G, Wiviott SD, Braunwald E, Murphy SA, Gibson $\mathrm{CM}$, McCabe $\mathrm{CH}$, et al. Prasugrel compared with clopidogrel in patients undergoing percutaneous coronary intervention for STelevation myocardial infarction (TRITON-TIMI 38): double-blind, randomised controlled trial. Lancet. 2009;373(9665):723-31.

48. Steg PG, James S, Harrington RA, Ardissino D, Becker RC, Cannon $\mathrm{CP}$, et al. Ticagrelor versus clopidogrel in patients with ST-elevation acute coronary syndromes intended for reperfusion with primary percutaneous coronary intervention: A Platelet Inhibition and Patient Outcomes (PLATO) trial subgroup analysis. Cir culation. 2010;122(21):2131-41.

49. Bellemain-Appaix A, Brieger D, Beygui F, Silvain J, Pena A, Cayla $G$, et al. New P2Y12 inhibitors versus clopidogrel in percutaneous coronary intervention: a meta-analysis. J Am Coll Cardiol. 2010;56(19):1542-51.

50. Erlinge D, Ten Berg J, Foley D, Angiolillo DJ, Wagner H, Brown PB, et al. Reduction in platelet reactivity with prasugrel $5 \mathrm{mg}$ in lowbody-weight patients is noninferior to prasugrel $10 \mathrm{mg}$ in higher-body-weight patients: results from the FEATHER trial. J Am Coll Cardiol. 2012;60(20):2032-40.

51. Kamoi D, Ishii H, Takahashi H, Aoyama T, Toriyama T, Tanaka M, et al. Sirolimus- vs. paclitaxel-eluting stent to coronary intervention in dialysis patients. Int J Cardiol. 2013;165(3):533-6.

52. Sardi GL, Loh JP, Torguson R, Laynez-Carnicero A, Kitabata H, Xue $\mathrm{Z}$, et al. Drug-eluting stents in patients on chronic hemodialysis: paclitaxel-eluting stents vs. limus-eluting stents. Cardiovasc Revasc Med. 2014;15(2):86-91.

53. Valgimigli M, Borghesi M, Tebaldi M, Vranckx P, Parrinello G, Ferrari $\mathrm{R}$, et al. Should duration of dual antiplatelet therapy depend on the type and/or potency of implanted stent? A pre-specified analysis from the PROlonging Dual antiplatelet treatment after Grading stent-induced Intimal hyperplasia studY(PRODIGY). Eur Heart J. 2013;34(12):909-19.

54. Silber S, Kirtane AJ, Belardi JA, Liu M, Brar S, Rothman M, et al. Lack of association between dual antiplatelet therapy use and stent thrombosis between 1 and 12 months following resolute zotarolimus-eluting stent implantation. Eur Heart J. 2014;35(29):1949-56.

55. Urban P, Abizaid A, Chevalier B, Greene S, Meredith I, Morice MC, et al. Rationale and design of the LEADERS FREE trial: A randomized double-blind comparison of the BioFreedom drug-coated 


\section{Summaria F et al.}

stent vs the Gazelle bare metal stent in patients at high bleeding risk using a short (1 month) course of dual antiplatelet therapy. Am Heart J. 2013;165(5):704-9.

56. Chang TI, Montez-Rath ME, Shen JI, Solomon MD, Chertow GM, Winkelmayer WC. Thienopyridine use after coronary stenting in low income patients enrolled in medicare part D receiving maintenance dialysis. JAm Heart Assoc. 2014;3(5):e001356.

57. Park SH, Kim W, Park CS, Kang WY, Hwang SH, Kim W. A comparison of clopidogrel responsiveness in patients with versus without chronic renal failure. Am J Cardiol. 2009;104(9):1292-5.

58. Morel O, El Ghannudi S, Jesel L, Radulescu B, Meyer N, Wiesel ML, et al. Cardiovascular mortality in chronic kidney disease patients undergoing percutaneous coronary intervention is mainly related to impaired P2Y12 inhibition by clopidogrel. J Am Coll Cardiol. 2011;57(4):399-408.

59. Htun P, Fateh-Moghadam S, Bischofs C, Banya W, Muller K, Bigalke $\mathrm{B}$, et al. Low responsiveness to clopidogrel increases risk among CKD patients undergoing coronary intervention. $J$ Am Soc Nephrol. 2011;22(4):627-33.

60. Alexopoulos D, Panagiotou A, Xanthopoulou I, Komninakis
D, Kassimis G, Davlouros P, et al. Antiplatelet effects of prasugrel vs. double clopidogrel in patients on hemodialysis and with high on-treatment platelet reactivity. J Thromb Haemost. 2011;9(12):2379-85.

61. Alexopoulos D, Xanthopoulou I, Plakomyti TE, Goudas P, Koutroulia E, Goumenos D. Ticagrelor in clopidogrel-resistant patients undergoing maintenance hemodialysis. Am J Kidney Dis. 2012;60(2):332-3.

62. Jeong KH, Cho JH, Woo JS, Kim JB, Kim WS, Lee TW, et al. Platelet reactivity after receiving clopidogrel compared with ticagrelor in patients with kidney failure treated with hemodialysis: a randomized crossover study. Am J Kidney Dis. 2015;65(6):916-24.

63. Herzog CA, Ma JZ, Collins AJ. Long-term outcome of renal transplant recipients in the United States after coronary revascularization procedures. Circulation. 2004;109(23):2866-71.

64. Summaria F, Manca Di Villahermosa S, Tedesco M, Lonzi M, Colarieti G, Chamoun MG, et al. Cardiovascular outcome in asymptomatic hemodialysis patients submitted to aggressive medical therapy: results of a four-year follow-up. Minerva Cardioangiol. 2011;59(2):121-6. 